\title{
MEMÓRIA E HISTORICIDADE EM DOIS "COMANDOS" PRISIONAIS
}

\section{Karina Biondi Adalton Marques}

\author{
L'histoire, ce n'est donc pas une durée, c'est une \\ multiplicité de durées qui s'enchevêtrent et s'enveloppent \\ les unes les autres. Il faut donc substituer à la vieille \\ notion de temps la notion de durée multiple. \\ Michel Foucault
}

Entre 2007 e 2009, desenvolvemos concomitantemente pesquisas sobre planos de relações profundamente entrecruzados, por vezes sobrepostos. Karina focou o funcionamento do Primeiro Comando da Capital (PCC) no interior das prisões paulistas a partir da descrição de como a política dessa organização é operada, especialmente no que tange à adição da noção de "Igualdade" aos seus "ideais". Tal acréscimo exigiu o acionamento de mecanismos e estratégias para garantir um "Comando" entre "iguais", e instaurou tensões em toda sua dimensão política ${ }^{1}$. Já Adalton concentrouse nos desdobramentos de uma possibilidade enunciativa que, segundo o entendimento dos interlocutores envolvidos, diferencia quem "tem proceder" daquele que "não tem proceder" ${ }^{2}$. Essa possibilidade enunciativa cintila nas unida-

${ }^{1}$ O PCC teve sua origem nas prisões paulistas na primeira metade da década de 1990 e hoje está presente em aproximadamente $90 \%$ das 147 unidades prisionais do estado de São Paulo (que abrigam aproximadamente 150 mil prisioneiros), bem como na maior parte das zonas urbanas do estado. A presença do PCC em áreas urbanas foi abordada por Biondi (2010) e Feltran (2007; 2008).

2 Todas as expressões ou termos nativos estão destacados por aspas. A palavra "proceder" geralmente é usada como substantivo ou como atributo de um sujeito; 
des prisionais do estado de São Paulo desde pelo menos a década de 1960.

Durante o desenvolvimento de nossas pesquisas, mantivemos um diálogo acerca de nossos dados e das problematizações que ofereciam. São muitos os pontos de aproximação e entrecruzamento entre os dois estudos. O presente artigo é resultado desse entrosamento e versa sobre um dos pontos em que nossas pesquisas se tocam. Trata-se do exame de alguns processos políticos que se intensificaram a partir dos primeiros anos da década de 1990, como o surgimento dos "comandos" no interior das prisões paulistas. Pode-se dizer, mais precisamente, que ocorreu uma partidarização (ou faccionalização, como preferirem $)^{4}$ de disposições heterogêneas que já tinham lugar nas relações entre nossos interlocutores": as "guerras" travadas entre esses coletivos políticos pelo "domínio das cadeias" e o embate de forças

raramente ocorre como verbo, designando alguma ação. No primeiro caso, corresponde ao conjunto de coisas tidas como "certas" num regime de relação. Sem dúvida, trata-se de um território bastante movediço no qual comumente ocorrem "debates" para se decidir o que é "o certo"; portanto, o que está em acordo com o "proceder". No segundo caso, a ocorrência dessa palavra se dá junto do verbo ter: "ele tem proceder" ou "ele não tem proceder" (Marques, 2006).

3 Sempre que utilizarmos a palavra "comando" com a inicial minúscula, referimonos genericamente aos coletivos prisionais. Nos casos em que tal palavra estiver grafada com a inicial maiúscula, reproduzimos um dos modos que nossos interlocutores utilizam para se referir aos seus próprios agrupamentos.

${ }^{4}$ A diferença entre partido e faç̧ão é tão somente "o produto de uma seleção ativa e temporária a ser recomeçada” (Deleuze e Guattari, 2005, p. 18). É apenas mais uma partilha entre bem e mal. Sabemos que essa diferenciação ancora-se na existência de algo como "o bem comum" ou "algum princípio acordado por todos" como "o interesse nacional" ou ainda "a democracia" -, ao qual os partidos concorreriam para a realização; já as facções o ignorariam. De outro modo não é possível diferenciá-los. Em suma, a partidarização (ou faccionalização) é um importante instrumento diplomático para a aliança com os pares, mas também um poderoso armamento para o embate contra os inimigos. Discussões acerca do conceito de facção podem ser encontradas em Boissevain (1974), Hardiman (1982), Nicholas (1977), Palmeira (1996), Sartori (1987), Schmidt et al. (1977) e Swartz (1968).

${ }^{5}$ Uma exposição pormenorizada sobre os processos de continuidade e de descontinuidade que (des)conectam o regime de relações que antecedeu a instauração dos grandes "comandos" paulistas, e esse mesmo acontecimento, foi elaborada por Marques (2009). 
(ou "guerra", também!) contra as agências estatais de segurança. O que traremos passa, efetivamente, por esse processo de partidarização.

\section{Estratégia metodológica e política}

Optamos por escrever este artigo na forma de um diálogo entre dois personagens inventados por nós, privilegiando a história do PCG e do Comando Revolucionário Brasileiro da Criminalidade (CRBC). É quase desnecessário dizer que invenção não implica déficit de realidade. Mas esse quase faz da defesa desse ponto de vista algo imprescindível. Esses personagens foram formados a partir da reunião de várias falas coletadas em nossos trabalhos de campo, em momentos distintos de nossas pesquisas ${ }^{6}$. Alguns enunciados tratavam de encontros entre prisioneiros dos "comandos" em questão, e outros se referiam aos oponentes. Muitas das formulações que compõem o diálogo que construímos sequer seriam cogitadas em um "debate" entre prisioneiros de "comandos" rivais, pois, de acordo com nossos interlocutores, "explicação se dá pra juiz; pra malandro não se explica”.

Cabe adiantar que optamos por manter algumas particularidades das falas nativas. Em função disso, o leitor vai se deparar com termos como "nóis" (nós) e "exturquir" (extorquir), e com formas abreviadas como "tamo" (estamos) e "cê" (você). Decidimos mantê-los ao invés de corrigi-los (e o mesmo vale para questões de concordância) pois entendemos que, longe de ser um desconhecimento gramatical da língua portuguesa, trata-se de uma opção por um estilo e uma cadência particulares. Até porque ambas opções - que privilegiam ou não a norma culta da língua - aparecem na linguagem nativa e são empregadas

\footnotetext{
${ }^{6}$ Nosso procedimento para obtenção de dados consistiu, resumidamente, na realização de conversas informais, principalmente com prisioneiros, ex-prisioneiros e familiares. A descrição pormenorizada dos procedimentos realizados foi exposta em nossas dissertações (Biondi, 2010 e Marques, 2009).
} 
de acordo com as exigências circunstanciais. Esta forma de uso da língua é uma opção que protesta, na voz de Mano Brown et al. (2002), contra menosprezos pedantes: "gíria não, dialeto". Pode-se dizer que estamos diante de uma subversão da linguagem.

Nosso objetivo, neste diálogo, é fazer aparecer a diferença manifestada pelo modo como cada um deles - um personagem relacionado ao PCC e o outro ao CRBC - compreende a história de "guerras" entre seus "comandos"; portanto, trata-se de apontar para processos distintos de constituição memorial e histórica ${ }^{7}$. Sem dúvida, essa diferença não é algo que aparece à totalidade dos interlocutores com os quais tivemos contato. "Todos os nativos sabem que..." é uma formulação criticada desde Malinowski. De certo modo, ao acentuar a disparidade de pontos de vista, oferecemos uma espécie de indicação (dentre outras possíveis) de leitura para compreensão das "guerras" entre "comandos". E

42 também conduzimos o leitor a um entendimento bastante específico acerca da conversação que se segue.

Não obstante, não se trata de um modo único e inequívoco de analisar esses processos. A ideia de escrevermos este artigo foi inspirada por discussões que tivemos, cada um com seu caderno de campo particular, acerca de qual trabalho de campo estava mais correto! Em meio a este diálogo pudemos enxergar que contávamos com pontos de vista divergentes. Não havia (nem há) contradições entre os pontos de vista, mas apenas diferenças! Como se verá na duração

\footnotetext{
${ }^{7}$ Segundo Adorno e Salla, "pouco se sabe efetivamente sobre as origens e a história da criminalidade organizada no estado de São Paulo". Além disso, segundo os autores, "o que se sabe sobre a emergência do PCC é ainda bastante insatisfatório" (2007, p. 25; nota de rodapé 3). Dizemos o contrário. Para nós, de outro modo, sabe-se muito sobre o "crime", bem como sobre o surgimento dos "comandos". E esse saber não se restringe apenas às contribuições de Mingardi (1998), Christino (2001) e Amorim (1993), citados por Adorno e Salla, e por certo bastante importantes. Antes, este conhecimento multiplica-se nos relatos dos próprios protagonistas dessa história, desde que sejam levados a sério.
} 
do diálogo, as atualizações pertencem inteiramente ao reino das perspectivas ${ }^{8}$.

Devemos expor, ainda, o modo como compreendemos nossa tarefa. Cabe-nos explicitar, portanto, tanto a questão que motivou este artigo quanto a maneira pela qual resolvemos encará-la. A questão: em que consiste a diferença entre os processos de constituição memorial e histórica que pode ser percebida no plano de relações sobre o qual se encontram os dois presos beligerantes? O tratamento: considerar o modo como cada um dos presos compreende essa diferença que cintila no plano de relações em que estão, eles próprios, inseridos. Dito de outro modo: trata-se de realizar um mapeamento dessa diferença a partir dos pontos de vista imanentes ao plano de relações perscrutado. Entendemos que a conexão entre a questão e o tratamento, expostos acima, deriva da forte aliança de trabalho que instauramos entre nós e, por conseguinte, do modo como empreendemos nossas pesquisas de campo. Esse método de trabalho, paulatinamente, e ao custo de muitas discussões belicosas, nos fez trocar as perspectivas que acessávamos a partir do encontro com nossos respectivos interlocutores. A percepção da existência de diferentes perspectivas permitiu que deixássemos de atribuir veridicidade aos dados recolhidos por cada um, bem como falta de exatidão aos dados do outro. Em outros termos, deixou de nos importar o registro do real a partir dos indicadores verdadeiro/falso, exatamente porque o real

\footnotetext{
${ }^{8}$ Nossa discussão acerca de perspectivas não está diretamente relacionada com o conceito de perspectivismo ameríndio (Lima, 2005 e Viveiros de Castro, 2002). Antes, está imbricada com o uso que Villela (2004) faz do termo, inspirado em Nietzsche: "O que chamo de perspectivismo e ponto de vista aproxima-se muito mais dos conceitos de sentido e interpretação em Nietzsche. [...] Conferir sentido e interpretação a uma coisa, a um órgão ou a um fenômeno em Nietzsche é o mesmo que assenhorar-se desta coisa, órgão ou fenômeno, sendo que essas sucessivas apropriações correspondem mesmo à sua história” (p. 22). O referido autor pretende dar conta das verdades parciais presentes em processos segmentares nos quais "a segmentação da história é influenciada pela segmentação dos grupos, ao mesmo tempo que esta última é determinada por aquela” (p. 23).
} 
se multiplicava a cada vez que trocávamos de ponto de vista. Coube, desde então, perceber como os valores "verdade" e "mentira" apareciam em cada ponto de vista que acessávamos. Daí por diante, só diferenças...9

Resta dizer que a decisão pelo formato de diálogo fictício deve-se a uma estratégia bastante precisa: fazer com que o $E u$ biográfico se despoje de si mesmo, imiscuindo-se, em solicitude ao conjunto de relações que o torna possível existir, nas vozes ausentes que, no entanto, falam-lhe na mesma língua. É que não nos importa o Eu que fala uma língua; enxergamolo somente como uma variável da mesma. Com efeito, queremos apresentar duas unidades que não têm nada a ver com biografias ou trajetórias, mas antes, com memoriais de embates.

\section{Um diálogo entre inimigos}

Zeta $^{10}$ foi chamado em seu "barraco" ${ }^{11}$, em um dos Centros de Detenção Provisória (CDPs) ${ }^{12}$ existentes na Grande São

44 Paulo, às seis horas da manhã. Já aguardava a convocação pronto, de banho tomado, barba feita, bem-arrumado, pois estava marcada para aquele dia sua audiência com o juiz responsável pelo processo que motivara sua detenção. Após criteriosa revista, foi encaminhado ao veículo que o transportaria ao Fórum Criminal da Barra Funda, zona oeste da cidade de São Paulo, na companhia de outros presos que também tinham compromissos com a Justiça.

O caminho para Zeta foi longo; antes de chegar ao seu destino o veículo parou em quatro unidades prisionais para

\footnotetext{
${ }^{9}$ Não vemos nesse procedimento de trabalho o domínio de um segredo milenar, mas antes, os efeitos de uma jovem disciplina que se ocupa de pontos de vista; essa é a mágica da antropologia.

${ }^{10}$ Optamos por nomear nossos personagens com letras gregas - Zeta $(\zeta)$, Sigma $(\sigma)$ e Delta $(\delta)$-, buscando fugir de quaisquer coincidências ou semelhanças que a escolha de nomes fictícios pudessem nos pregar.

11 "Barraco", para os prisioneiros, é o mesmo que "cela".

${ }^{12}$ Os CDPs, de acordo com o Decreto $\mathrm{N}^{\circ} 44.708$, de 10 de fevereiro de 2000, são aparelhos "destinados à custódia de presos provisórios", ou seja, aqueles que aguardam julgamento.
} 
recolher outros detentos. No interior escuro do caminhão, os presos, algemados uns aos outros, sequer tinham lugares suficientes para se sentarem. Tudo isso, somado ao balanço do veículo e ao calor causado pelo sol que já batia em sua lataria, fazia com que alguns deles vomitassem. Outros tinham crises respiratórias em função do gás carbônico liberado pelo caminhão. Um deles chegou a desmaiar ${ }^{13}$. Uma parada mais longa fez com que começassem a protestar: "Abre aqui! Tamo fritando nessa lata!". Um dos policiais respondeu: "Cala a boca, vagabundo!". Com isso, iniciou-se uma troca de insultos que só teve fim quando os policiais decidiram usar gás de pimenta. O veículo, então, seguiu seu caminho, enquanto os prisioneiros mal conseguiam respirar.

Finalmente Zeta chegou ao seu destino. Embora estivesse bem fisicamente, não ficou ileso à tensão que o acompanhara naquele trajeto. Quarenta e dois prisioneiros "atracaram"14 no Fórum Criminal da Barra Funda. Eles foram retirados do "bonde" de sete em sete e encaminhados a um espaço reservado aos prisioneiros que lá chegavam. Antes de entrar em uma das sete celas que havia naquele espaço, cada preso foi revistado por um policial.

Após algum tempo de espera, Zeta foi chamado para que fosse encaminhado com outros três prisioneiros à Vara de Execuções correspondente aos processos a que respondiam. O policial que os escoltara ordenou que mantivessem as cabeças baixas, que não dirigissem o olhar a ninguém. Mesmo assim, no caminho, Zeta pôde ver sua mãe, seu irmão e duas testemunhas de acusação. Em fila e algemados uns aos outros, chegaram à Vara, onde havia um corredor com duas celas: uma reservada a prisioneiros provenientes de "cadeias

\footnotetext{
${ }^{13}$ As características desse transporte de prisioneiros (os "bondes", como eles o chamam) estão presentes em todos os relatos que possuímos. Essas narrações sempre se convertem em denúncias que descrevem desde ligeiros mal-estares sofridos durante o percurso até reações físicas que colocam as vidas dos prisioneiros em risco. ${ }^{14}$ Neste caso, "atracaram" é o mesmo que "chegaram".
} 
do PCC" e outra àqueles oriundos de prisões de "outros comandos" 15 . Novamente o policial ordenou que mantivessem a cabeça baixa e que não olhassem para os prisioneiros que estavam na primeira cela. Na segunda, onde Zeta entrou, havia cerca de quarenta detentos, todos provenientes de "cadeias do PCC". Enquanto aguardava sua audiência, outros presos chegaram e alguns saíram. Embora a cela ao lado não estivesse em seu campo de visão, percebeu que a movimentação ali era muito menor.

O "bonde" de Sigma até o Fórum Criminal da Barra Funda foi parecido com o de Zeta, ainda que não tenha parado em outras unidades prisionais; por isso, a viagem foi bem mais rápida. $\mathrm{O}$ desembarque dos catorze detentos que chegaram ao Fórum foi similar ao desembarque do "bonde" que 46 levou $\mathrm{Zeta}^{16}$. Durante o trajeto percorrido entre a unidade

${ }^{15}$ Entre os demais "comandos" estão a SS (Seita Satânica), o CDL (Comando Democrático da Liberdade) e o TCC (Terceiro Comando da Capital), além do CRBC, atualmente o maior e mais expressivo deles. Estas formulações nativas sobre a posse das cadeias ("cadeias do PCC", "cadeias do CRBC" etc.) não se opõem à questão da gestão das prisões pela Secretaria da Administração Penitenciária. Como veremos adiante, tais enunciações derivam da luta territorial travada entre os "comandos", designada "guerra" por nossos interlocutores.

${ }^{16}$ A diferenciação do percurso do "bonde" (com várias paradas ou sem paradas) decorre do número de prisões destinadas a custodiar presos relacionados ao CRBC. Não sabemos com precisão quais são estas prisões - exceções são a Penitenciária José Parada Neto, a Penitenciária de Itirapina II e o CDP II de Guarulhos mas nossas pesquisas indicam que estão em número absolutamente inferior ao de prisões destinadas a abrigar prisioneiros relacionados ao PCC. Por esta razão, também, o número de detentos que compuseram o "bonde" de Zeta é muito maior do que o de presos que dividiram "bonde" com Sigma. Embora saibamos que o número de "cadeias do PCC" é maior que o número de "cadeias do CRBC", os domínios territoriais são tão perspectivistas quanto as histórias dos "comandos". Os dados de nossos cadernos de campo divergiam e, mais uma vez, não se tratava de contradição. Ambos os mapeamentos são reais, são verdadeiros. Por exemplo: Adalton coletou relatos que afirmavam ser do CRBC, ao menos parcialmente, uma unidade prisional localizada na Grande São Paulo. Karina, por sua vez, tinha referências a esta mesma unidade como "dominada pelo PCC". Neste caso, pode ser que os prisioneiros do PCC tenham esta unidade como "cadeia do comando", 
prisional e o Fórum, não houve discussão entre detentos e policiais ${ }^{17}$. Mas nem por isso Sigma e os outros detentos que compunham aquele "bonde" estavam livres de certa tensão. Ela não vinha exclusivamente da situação do transporte e nem dos enfrentamentos entre policiais e detentos, mas residia em outro conjunto de preocupações: a cela para a qual os presos seriam encaminhados. Por isso, ao chegar ao corredor onde estavam localizadas as celas destinadas aos presos que se apresentariam ao juiz daquela Vara, Sigma se dirigiu aflito ao policial:

Sigma: Senhor, a cela que o senhor tá me mandando não é do PCC, né?

Policial: Vai seu vagabundo do caralho, te jogo onde eu quiser! Você é seguro ${ }^{18}$, né? Aqui você tem medo, né, seu vagabundo?

Sigma: Você tá me tirando?! Aqui não tem seguro porra nenhuma.

por considerarem o pavilhão do CRBC como um raio para o qual são destinados aqueles presos que pedem refúgio (ou "pedem seguro", como expressam) à administração prisional. A partir de outra perspectiva, os prisioneiros do CRBC sabem que podem ser transferidos para esta unidade tranquilamente, sem que suas vidas sejam postas em risco, pois lá há um território que é do CRBC.

${ }^{17}$ A ausência de enfrentamento será abordada adiante, durante o diálogo entre Sigma e Zeta.

18 "Seguro" é o nome que se dá aos espaços prisionais reservados pela administração prisional aos presos que pedem sua salvaguarda. Nas "antigas" (modo como os presos se referem ao tempo em que não havia "comandos") esses espaços eram ocupados por estupradores, justiceiros, devedores (quase sempre por conta do uso excessivo de drogas), delatores, presos que encontravam inimigos na prisão e não estavam dispostos a enfrentá-los etc. Contra os presos que "pediam seguro" recaía a negação de um atributo imprescindível para as relações sociais dos presos paulistas: o "ter proceder". Atualmente, momento em que as posses territoriais dos "comandos" estão relativamente sedimentadas - isso se compararmos às grandes "guerras" que ocorreram entre a metade da década de 1990 e os dois ou três primeiros anos de nosso decênio -, "seguro" costuma ser os espaços prisionais, e até mesmo as unidades prisionais, que estão fora do campo de atuação do "comando" ao qual se está relacionado. Diz-se, hoje, que nos "seguros" estão, além das figuras citadas acima, os inimigos do "comando". Mais uma vez estamos num jogo perspectivo: nos "seguros" do CRBC há presos do PCC em trânsito e vice-versa. Para uma análise acerca das correlações entre "proceder" e a espacialidade da prisão, ver Marques (2006; 2009). 
Policial: Cala a boca, vagabundo! - gritou, enquanto dava um soco no estômago dele e o empurrava para dentro da cela.

Sigma: Gambé ${ }^{19}$ desgraçado! - disse aos berros.

A conturbada chegada de Sigma na cela ao lado chamou a atenção de Zeta. Pela primeira vez em quatro anos de comparecimento a fóruns, presenciou um "coisa" peitar a polícia ${ }^{20}$. Ficou surpreso, já que ouvira sempre dizer que os presos de "cadeia do CRBC" cooperam com policiais. Ao ouvir a tranca se fechar, um intenso debate teve início:

Zeta: E aê, coisa braba! Resolveu bater de frente com os coxinha?

Sigma: Cala a boca, ô lagartinho do $\mathrm{PCC}^{21}$ !

Zeta: Eu vou arrancar a sua cabeça ${ }^{22}$ !

Sigma: Você nem me conhece. Tá falando o quê?

Zeta: Nem preciso conhecer. Você é coisa ${ }^{23}$ e eu vou arrancar tua cabeça!

Sigma: Onde eu passei pelado, você não passa nem blindado.

\footnotetext{
19 "Gambé" e "coxinha" são termos empregados pelos prisioneiros para se referirem aos policiais.

${ }^{20}$ Este é o modo como os presos de "cadeias do PCC" compreendem os presos de "cadeias de oposição", que inclui não só o CRBC mas também os outros coletivos de presos citados na nota 15. A noção de "coisa", neste caso, significa um modo particular de cooperação com a política de administração prisional, na qual está implicada a abdicação dos projetos de fuga. Tal conduta é considerada avessa à "Liberdade", um dos princípios basilares da política do PCC (expressa no lema "Paz, Justiça, Liberdade e Igualdade").

${ }^{21}$ Esta é a categoria com a qual os presos de "cadeias do CRBC" designam o modo como os presos de "cadeias do PCC" conduzem suas existências. "Lagarto" é aquele que aceita permanecer no jugo de outro em troca de proteção. É importante frisar que a existência do "lagarto" se dá na relação com aquele "que exturqui" e "que oprime".

${ }^{22}$ A decapitação tornou-se uma marca do PCC, em suas "guerras" com outros "comandos" prisionais.

${ }^{23}$ A divisão espacial - uma cela para os presos do PCC e outra para os presos do CRBC - está diretamente implicada na classificação ("coisa”) que Zeta faz de Sigma.
} 
Zeta: Se você anda desfilando pelado na cadeia, malandro... Quer que eu fale o quê? Tá lavando coruja ${ }^{24}$ de vagabundo. Por isso tá no seguro!

Sigma: Falô, viu? Em cadeia que você passou eu também passei.

Zeta: Aê! Você tá louco? Passou o quê? Passou aonde?

Sigma: Isso mesmo! Já tirei cadeia feito Mandela ${ }^{25}$. Você não conhece a minha caminhada ${ }^{26}$.

Zeta: Se você tá desse lado aí, você é coisa. Na cadeia que eu tiver, você não entra.

Sigma: E nem quero entrar. Já basta o que vi. Tá ligado o irmão Delta ${ }^{27}$ ? Corri lado a lado ${ }^{28}$ com ele. Fui faxina ${ }^{29} \mathrm{com}$ ele faz uma cara no Carandiru ${ }^{30}$. Esse irmão corria pelo certo ${ }^{31}$ e seus companheiros aí mataram o cara.

Exatamente neste instante, Sigma recordou-se do seu grande parceiro ${ }^{32}$. Um pensamento ecoou em sua mente:

24 "Coruja" é o mesmo que "cueca". Esta frase costuma ser proferida para acusações de submissão sexual, quase sempre enunciada como ofensa.

${ }^{25}$ Esta é uma expressão muito comum entre os prisioneiros para caracterizar aqueles que cumpriram ou ainda estão cumprindo penas longas.

26 "Caminhada" é uma palavra nativa relativa à história. "Você não conhece a minha caminhada" é o mesmo que "você não conhece a minha história".

27 "Irmão" é o membro "batizado" no PCC. Contudo, esse coletivo político não se restringe a um conjunto de "irmãos". Biondi (2010) explora como a atuação desse "comando" independe da presença de membros "batizados"; seu funcionamento também está garantido por outras pessoas, a quem chamamos aqui de relacionados ou relativos ao PCC.

28 "Correr lado a lado" é o mesmo que "ser um aliado".

29 "Faxina" é uma atividade política que já existia antes do aparecimento dos comandos e persiste ainda hoje, em seu interior (Biondi, 2010 e Marques, 2008). Guardadas as diferenças no decorrer do tempo e nos diferentes "comandos", o "faxina" é um prisioneiro responsável por determinadas tarefas cotidianas internas ao seu pavilhão (como a distribuição de comida e remédios), mas também por dar soluções a litígios entre prisioneiros e atuar nas negociações com a administração prisional.

${ }^{30}$ Com a expressão "faz uma cara", Sigma quis dizer "há muito tempo". Carandiru é o nome como ficou conhecida a Casa de Detenção de São Paulo, instituição penal que chegou a abrigar quase 8 mil homens. Em 2002, foi completamente desativada e implodida para dar lugar a um parque.

31 "Correr pelo certo" é o mesmo que "ter proceder".

${ }^{32}$ É importante notar que os relatos de nossos interlocutores não se restringem ao que é manifestado nas conversas. Antes, são recheados de pensamentos, estraté- 
"Vixi... Mili duque... ${ }^{33}$ Esse maluco era firmão. Saudades dele."

Zeta: Ninguém morre à toa. Se mataram, foi porque o cara deu motivo.

Sigma: O cara tava defendendo o certo. O cara morreu defendendo o certo. Ele não aceitava as fita ${ }^{34}$ errada que tavam rolando. Uma pá de cara do PCC exturquindo os companheiros de sofrimento...

Nesse instante, Sigma foi interrompido pelo seu desafeto.

Zeta: Que exturque o caralho! Se você diz ter corrido com o Partido ${ }^{35}$, sabe que essas patifaria não existe. $\mathrm{O}$ Comando veio acabar com isso aí, vagabundo!

Sigma: Eu não tô dizendo que não. O irmão Delta corria mesmo pelo certo. Só que a fita já não é mais a mesma, né?

Enquanto Sigma falava, Zeta lembrou do irmão Delta e pensou consigo mesmo: "Porra, esse maluco vivia passando pano pra uma pá de cara errado... era o maior alfaiate" 36 .

Zeta: É, a fita já não é a mesma porque demos um fim em pilantras como o irmão Delta.

Sigma: Isso mesmo, seu réptil. Vocês deram um fim no cara que corria pelo certo no PCC, que acreditava no que era para ser o PCC no início de tudo: um comando que acabasse com as fita de um preso exturquir o outro.

gias, avaliações e reflexões. Com efeito, as narrativas discorrem sobre um conjunto de coisas não ditas, porém existentes.

33 "Mile duque" possui o mesmo sentido de "faz uma cara". Ver nota 30.

34 "Fita", nesse contexto, é o mesmo que "situação".

35 "Partido" é uma das maneiras com que os prisioneiros se referem ao PCC. "Quinze" também. Nesse caso, trata-se de uma abreviação de 15.3.3, números que correspondem, de acordo com a ordem das letras no alfabeto, a PCC.

36 "Passar pano" é o mesmo que defender ou encobrir alguém que "está pelo errado". Por conseguinte, "ficar no pano" corresponde a estar sob proteção de outrem. "Alfaiate", por sua vez, é uma referência a alguém que recorrentemente "passa pano". 
Zeta: Que você sabe do Quinze? Presta atenção nessas palavras aí, ô! Quem tá no seguro é você, não é nóis, coisa braba.

Sigma: Sabe por que um cara igual a eu, $157^{37}$, faxina em várias cadeias que tirei, que nunca fui para o seguro, que nunca tirei ninguém, que sempre fui humilde com os humildes, que nunca amarelei pra ninguém... Sabe por que não havia possibilidade de eu ficar numa cadeia do PCC? Porque vocês não têm proceder! Quem tinha proceder, no começo, e queria acabar com as patifaria, foi morto ou expulso. Preferi sair fora.

Zeta: Se o Comando deu oportunidade pra você e você não foi digno...

Agora foi a vez de Zeta sofrer interrupção:

Sigma: O PCC não me deu oportunidade, não. Eu representei o crime ${ }^{38}$ pra caramba. Eu fiz 99[\%]... Na minha opinião eu fiz mais de 100 [\%], mas pra vocês eu fiz 99[\%]. Não fiz 100 [\%], não vale de nada os 99[\%]. E sabe o que foi o 1[\%] que vocês cobraram? A mêma fita do falecido irmão Delta: de eu não ter deixado seus irmãos exturquir um humilde.

Zeta: A fita é a seguinte, quando precisávamos ganhar as cadeias teve uma pá de vagabundo que dizia que corria com nóis que queria passar pano pra pilantra. Se você e o irmão Delta passaram pano pra pilantra é a cara do Partido não fechar com vocês ${ }^{39}$. Quem corre com errado, errado é! Ou corre com o Comando, ou já era! Se não tá com nóis, tá contra nóis!

\footnotetext{
${ }^{37}$ Referência ao artigo 157 do Código Penal, que trata, dentre outras coisas, de assalto à mão armada.

38 "Representar o crime" é o mesmo que nutrir um conjunto de alianças entre "ladrões". Cabe sublinhar que, para nossos interlocutores, "crime" não se reduz, em absoluto, à efetuação de ações passíveis de punição penal.

${ }^{39}$ A expressão "é a cara do Partido não fechar com vocês" denota que as características do PCC são incompatíveis com aquelas condutas, motivo pelo qual uma aliança seria inviável.
} 
Sigma: É esse mêmo o proceder do cara que fez vocês de lagarto uma cota, aquele estuprador do Geleião ${ }^{40}$. Veja só! Vocês ficaram no pano de um pilantra da pior qualidade.

Zeta: A fita não foi a mesma. A fita que você citou foi quando o Comando tava se firmando; tinha uma pá de pilantra que tinha que morrer mesmo. Era nossa cara acabar com as pilantragem que tinha no sistema. E não tem como fazer isso sem mostrar quem estava no comando. Outra parada foi o Geleião. Só questão de tempo pro certo prevalecer! O Geleião fez as pilantragem dele e não passou impune pelo Comando. Agora ele é o maior seguro do mundo. Nossa justiça pode tardar, mas não falha. O que é certo, aparece. Não tem jeito. A mixa dele caiu! ${ }^{41}$ Mas isso é passado pro Comando!

Sigma: Só tem um PCC: um bando de lagartos, de pau-mandado! Não existe outro PCG!

Zeta: Na época que você diz que tava correndo com o PCC, podia até ter lagarto. Só que nós não aceitamos esses 52 lagarto enrustido de malandrão. Por isso que corre tudo pro seguro. Olha você aí! E tem mais: no PCC não tem mais lugar pra malandrão. O Marcola ${ }^{42}$ revolucionou o sistema!

\footnotetext{
${ }^{40}$ Geleião foi um dos oito fundadores do PCC. Sabe-se que, próximo ao ano 2000, ou em 2001, ele e Césinha - então os únicos fundadores vivos - potencializaram enormemente as diferenças hierárquicas no interior do PCC, inclusive com a criação dos postos de "generais". Esse período é lembrado com muito desprezo pelos presos relacionados a esse "comando". Considera-se que foi uma época de deturpação dos próprios "ideais do PCC". Ao final de 2002 eles foram expulsos desse coletivo que, por sua vez, acrescentou o princípio de "Igualdade" ao seu lema. Tal foi a forma de marcar uma diferença fundamental em relação ao período anterior e de impedir novas proliferações de "desigualdade no Partido".

41 "A mixa dele caiu" é o mesmo que "a verdade veio à tona".

${ }^{42}$ Tal como as várias histórias existentes acerca do PCC e do CRBC, existem vários Marcolas, que são construídos a partir de pontos de vistas específicos. Para o poder público, ele é o "líder máximo do PCC". Diferentemente, os presos do PCC não o veem como uma pessoa que manda ou detém o poder, mas como uma pessoa que "tem o respeito" deles. Na visão dos presos relacionados ao CRBC, que se aproxima do ponto de vista do poder público, ele é tido como alguém que exerce o mando que fora exercido por Geleião. Uma problematização acerca da noção de "liderança" comumente atribuída a Marcola é apresentada em profundidade por Marques (no prelo).
} 
Sigma: O Marcola é só mais um que lagarteia os outros. Deve estar com o cu cheio de grana enquanto vocês se matam pra dar dinheiro pra ele...

Zeta: Quem dá dinheiro?

Sigma: Vocês! Todo mundo sabe que pra ficar em cadeia do PCC tem que pagar.

Zeta: Mais uma vez o lagarto do seguro tá falando merda! Chapéu atolado ${ }^{43}$ ! Você não diz que passou em cadeia do PCC? Você pagou alguma coisa? Se pagou, você é lagarto mesmo! Agora cê vem falar que o Partido exturque os presos?

Sigma: Se a obrigação de pagar não é exturquir, eu já não sei o que é!

Zeta: Mas ninguém é obrigado a nada...

Sigma: O que é ser ladrão? Ladrão é o cara chegar e roubar e fazer a caminhada dele, certo? Eu não pago nada pra ser bandido. Agora, você, pra poder dizer que é bandido, tem que pagar. Eu não pago.

Zeta: Eu tô fazendo pelo certo... não é por aí... o bagulho não é obrigado... tô fazendo uma pelo certo...

Sigma: Eu não tenho que pagar pra ser ladrão.

Zeta: Eu também não preciso pagar pra ser ladrão, mas também não deixo meus irmão no sofrimento. Eu dou assistência pra eles...

Sigma: Viu só: lagarto!

Zeta: Dar assistência não é ser lagarto! É correr lado a lado, o que vocês não sabem o que é, porque aí é um querendo acabar com o outro. Não tem a união que nóis tem. É um por todos e todos por um!

Sigma: O seu PCC é um bando de moleques no pano um do outro, mandando para o seguro uma pá de cara que são mais ladrão que eles ${ }^{44}$.

\footnotetext{
43 "Chapéu atolado" é uma referência a alguém que não consegue enxergar a situação, que não vê a realidade.

44 "Ladrão", neste caso, é um qualitativo positivo.
} 
Zeta: Se corre pro seguro, nem malandro é! Porque malandro que é malandro vai debater as fita dele. O PCC vai dar oportunidade pra ele debater. Só que quando o ladrão é pilantra, ele corre mesmo.

Sigma: O que você chama de pilantra são os manos que não aceitam ser lagartos.

Zeta: Ninguém aqui aceita ser lagarto. Essa fita já era! Era coisa do Geleião e o bolinho podre dele ${ }^{45}$, que o poder subiu pra cabeça e começou a usar o Partido pra fins pessoais. Foi por isso que botamo esses caras pra correr. Não tiveram disposição pra trocar ${ }^{46}$ e saíram escorraçados. Agora aqui só fica quem corre com o certo, quem sabe ser de igual, na humildade, quem corre com a disciplina do Comando.

Sigma: Mas eu tô ligado que tem uma pá de mano que segura as fita dos irmãos ${ }^{47}$.

Zeta: Vagabundo, a caminhada é assim. Tem malandro 54 na cadeia que dá o passo maior que a perna, que se endivida e é pobre-louco-na-ilha ${ }^{48}$. Aí ele faz os corre dele.

Sigma: Tá aí uma fita que não admitimos. Aqui não tem lagarto. Se o cara quer ser lagarto, que vá pra cadeia do PCC.

Zeta: Então se o cara é pobre-louco, quer fumar um baseado, não pode? Quer correr atrás de umas peça, não pode? Então se o cara é pobre-louco-na-ilha não pode fazer nada? Quem tá oprimindo? Quem é o lagarto?

Sigma: Nós execramos qualquer atitude que lembre o PCC. Aqui ninguém aceita ser lagarto. Não tem lagarto e ponto!

\footnotetext{
45 "Bolinho podre" é uma referência a qualquer agrupamento de presos que planeja, executa ou conspira contra uma pessoa ou contra o coletivo.

46 "Trocar", neste caso, significa "ir às vias de fato em um combate".

47 "Segurar as fita", nesse caso, corresponde a assumir o cometimento de alguma falta disciplinar ou mesmo de um crime.

48 "Pobre-louco-na-ilha" ou "pobre-louco" é o prisioneiro que não recebe visitas e não tem parentes ou amigos que o auxiliam, enviando-lhe, por exemplo, objetos de uso pessoal ("peça", na linguagem nativa) como aparelho de barbear, sabonete ou papel higiênico.
} 
Zeta: Só que uma coisa é não aceitar ser lagarto e outra coisa totalmente diferente é quando o cara quer humilhar e exturquir, quando quer ser mais que os outros. Se o cara faz uma dívida e tem que pagar, e ele não tem família que dá assistência, daí ele resolve fazer o corre de segurar o biriri ${ }^{49}$ de alguém, quem sou eu pra dizer que ele não pode? Sou mais do que ele? Não sou, certo? É um corre. Não é bem visto. Mas se o cara quer fazer, quem sou eu pra falar que não? Pra que vou humilhar o irmãozinho? Da caminhada dele é ele quem sabe. Eu ando com as minhas pernas. Quem tá quebrando as pernas dele é ele mesmo. A gente instrui o cara, pra ele não se endividar e tal... Mas o cara tem a liberdade dele.

Sigma: Liberdade de ser lagarto não é liberdade!

Zeta: $\mathrm{O}$ que você sabe de liberdade se você nem faz uma pra fugir? Se você goza a cadeia e corre lado a lado com a polícia, com os agente?

Sigma: Liberdade pra mim é tirar minha cadeia na bolinha de meia ${ }^{50}$. Cumprir minha pena na moral e ir pra rua.

Zeta: E correr com polícia!

Sigma: Eu não quero ficar a vida inteira preso! Quem gosta de tirar cadeia são vocês, que arranjam mais e mais motivos pra pena aumentar.

Zeta: Presta atenção nas palavras que você tá falando aí, seu verme! Vocês não podem fazer qualquer corre pra fugir, senão os polícia manda vocês de "bonde" pra cadeia do Partido, né? É essa a triste realidade do seu comando: vocês são pequenos, um bando de iniciantes.

Sigma: Ladrão que é ladrão, desde as antigas, é aquele que quer voltar pra rua pra fazê sua correria. O que importa é a correria da rua, não de cadeia. O movimento tá na rua.

Zeta: Por isso mesmo! Se prezassem tanto assim se empenhariam pra fugir. Quer saber, vocês não tão em cadeia do

\footnotetext{
49 "Biriri" é o mesmo que "aparelho celular".

50 "Tirar cadeia na bolinha de meia" é o mesmo que "cumprir pena sem se envolver em confusões".
} 
Quinze porque não têm disposição pra quebrar cadeia e pra bater de frente com a polícia ${ }^{51}$. O barato de vocês é gozar a cadeia. Vocês tão gozando na cadeia do titio Alckmin, né ${ }^{52}$ ?

Sigma: Quem tá na frente de nosso comando tem visão ${ }^{53}$.

Zeta: Visão de jatobá ${ }^{4}$ !

Sigma: Quem tá aqui na frente não é esse bando de moleque que quer fazer nome. Ninguém impede fuga. Diferente de vocês que querem que todos façam uma só pra falar que representou no crime. Na hora do pá mesmo, só uns poucos podem fugir. Aí, corrê com o comando de vocês é lucro só pros seus irmãos, né? Não tem vez pra quem quer fazer a caminhadinha no sossego. Vocês oprimem esse cara.

Zeta: Quem quer ficar na cadeia, vai pra igreja! Nossa cara $^{55}$ é quebrar cadeia, seu coisa. É bater de frente com a polícia. Não é ficar deitado na jega ${ }^{56}$ esperando quarenta ano passar.

Sigma: É isso mesmo! Daí vocês se sentem na razão de 56 fazer todo mundo ter a mesma caminhada de vocês. É isso que chamam de igualdade, de humildade? Os irmãos ditam o que é o certo e o resto dos lagartinho tem que fazer a mesma caminhada.

Zeta: E vocês dizem pro mano que tá no desespero que ele não tem que fugir! Cadê a igualdade de vocês? O cara não pode tentar a sorte dele!

\footnotetext{
51 "Quebrar cadeia" (tentar fugir ou fazer rebeliões) e "bater de frente com a polícia" (manter postura oposicionista) constituem importantes diretrizes na política do PCC (Marques, 2006; 2008 e Biondi, 2010).

${ }^{52}$ Esta é uma referência comum, entre os prisioneiros, às unidades prisionais construídas durante o mandato de Geraldo Alckmin, ex-governador do estado de São Paulo.

53 "Ter visão", na concepção nativa, é muito mais do que ser dotado de um fator sensorial. Alguém que "tem visão" é uma pessoa capaz de avaliar a situação e as circunstâncias em que está envolvido.

${ }^{54}$ Acusar alguém de ter uma "visão de jatobá" é o mesmo que dizer que esta pessoa não tem visão.

${ }^{55}$ Por "nossa cara", nesse contexto, quer-se dizer "nossa característica diferenciadora",

56 "Jega" é o nome que os presos dão à cama de concreto existente nas celas.
} 
Sigma: A gente só instrui o cara.

Zeta: É a gente que instrui o que é o certo.

Sigma: Tirando uns poucos que tavam pelo certo no começo do PCC, que queriam acabar com as patifarias que existia, não tem mais o certo no PCC.

Zeta: Não fala bosta! Tirando o Geleião e seu bolinho podre, que foram tudo escorraçado, não tem o que falar do nosso comando. E tem mais, o PCC de agora não tem nada a ver com o que era antes. Nós aprendemos com os erros do passado. Não bastou nossa luta pela liberdade, pela justiça e pela paz entre os irmão. O PCC de agora também luta contra o que não é de igual.

Sigma: Vocês gostam de ser lagarto desse Marcola. Ele corria lado a lado com o Geleião. Oprimiram uma pá de mano que atracou no nosso comando e hoje vive bem, com respeito.

Zeta: O Marcola é só mais um. O cara é mais humilde que qualquer um. É o maluco mais de igual que existe ${ }^{57}$. Não tem nada a ver com o verme do Geleião.

Sigma: Os caras do PCG que estavam pelo certo morreram na mão de outros que tão até hoje por aí, pagando de igualdade. O resto que tinha de cara pelo certo no Carandiru tá tudo com nóis. Não adianta vocês mudarem de Geleião pra Marcola. Vão continuar sendo uma pá de lagarto.

Zeta: Nosso comando não para de crescer, ô seu coisa! É porque nós tamo pelo certo! Por causa do PCC, tirar cadeia hoje tá mamão com açúcar, ficou muito mais suave ${ }^{58}$.

\footnotetext{
${ }^{57}$ Neste contexto, ser "só mais um" é um grande elogio. É um indicativo de não ser (ou não querer ser) "mais que os outros". Sobre a questão da "igualdade" no PCC, ver Biondi (2010).

${ }^{58}$ Dizem os prisioneiros "antigos" que se aliaram ao PCC que o cumprimento da pena ("tirar cadeia") após o aparecimento e a consolidação do "Comando" se tornou "mamão com açúcar". Ou seja, tal situação é muito mais tranquila em função da preferência pela regulação de conflitos entre prisioneiros por meios não letais, e ainda pelo que os membros do PCC consideram "conquistas" frente à administração prisional, como a existência de visitas íntimas. Segundo eles, as políticas colocadas em operação pelo PCC foram responsáveis pela diminuição do número
} 
Sigma: E depois somos nós que gostamos de tirar cadeia...

Zeta: Não tem nada a ver essa história aí. A fita é que aqui não tem mais malandrão oprimindo e exturquindo. Esses vermes tão tudo aí do seu lado. Nós vamos acabar com vocês. Vocês são o lixo da Terra. Coisa braba!

Sigma: Seu verme. Vocês são um bando de verme.

Zeta: Eu vou é arrancar sua cabeça!

Sigma: Tenta a sorte! Pouca ideia ${ }^{59}$ !

Nesse exato momento os dois presos beligerantes foram surpreendidos por dois policiais enfurecidos por conta do barulho daquela discussão.

\section{Diferenciações memorial e histórica}

O diálogo que acabamos de acompanhar poderia ter sido mais um breve capítulo da intensa história de "guerras" 58 entre PCC e CRBC. Certamente as acusações e ameaças recíprocas repercutiriam em encontros vindouros, nos quais, talvez, condições propícias para matar e para morrer estariam colocadas. Há algo de perturbador nisso tudo. Sem dúvida. Mas somente um humanista poderia terminar esse diálogo de modo diverso - por humanista chamamos aqueles que se dedicam a equacionar relações de conflito, que consideram negativas (moralmente, pois são más; e filosoficamente, pois não são atualizações do ideal), através da exposição de valores que estimam serem preeminentes no Homem e no Mundo. Nós não contamos, aqui, com valores como Ordem, Consenso e outros avatares. Portanto, não poderíamos terminar o diálogo de outro modo. Não poderíamos, com efeito, propor qualquer resolução para as diferenças que existem

de homicídios dentro dos cárceres. Da mesma forma, há anos os moradores das periferias de São Paulo atribuem ao PCC a responsabilidade pela queda acentuada da taxa de homicídio no estado (ver Biondi 2007a; 2007b; 2008).

59 "Pouca ideia" é uma forma de desafiar o oponente a um combate corporal. 
entre nossos personagens por meio de valores externos ao plano em que eles se relacionam (ou melhor, "guerreiam"). Contamos somente com as relações (belicosas) que se atualizam em tal plano. Nosso objetivo foi tão somente mapeálas. Mais precisamente, cartografar a diferença manifesta pelo modo como cada um de nossos personagens compreende a história de "guerras" entre seus "comandos".

Vejamos algumas linhas gerais desse mapa. Inicialmente, é importante pontuar que a história do CRBC aparece como um único bloco, sem transformações, para os dois pontos de vista do plano. Para Zeta esse "comando" é, sempre foi e sempre será um agrupamento de "coisas”. Já Sigma, de modo diverso, considera seu "comando" como o "último lugar em que ainda vigora o proceder pelo certo”. Apesar das diferentes apreciações, simetricamente opostas - repulsa e afeição -, ambas são caracterizações acerca de um processo histórico sem cortes, monolítico e monocromático.

Mas essa é somente a história de um dos lados desse embate de forças. $\mathrm{O}$ modo como esses pontos de vista veem a história do PCC é algo um pouco mais complexo. Para Sigma, o surgimento desse "comando" foi acompanhado por um sentimento esperançoso quanto à extirpação dos males impregnados nas relações sociais da prisão: a extorsão entre presos e as "rupas" ${ }^{00}$ desenfreadas. Tal sentimento foi sustentado pelas providências e intervenções que alguns "irmãos" daquela época começaram a fazer pelas cadeias em que passavam. Sigma lembra desse PCC como um coletivo que disputava territórios com dezenas de quadrilhas que aterrorizavam os "presos humildes" pelas prisões paulistas. O "comando" em questão não possuía as codificações de um estatuto, estava longe de possuir supremacia territorial e ainda faltavam alguns anos para que chegasse o dia das "grandes guerras" de que participaria. Porém, ainda

60 "Rupa" é nome que se dá à matança de vários presos ao mesmo tempo. 
nessa época, dissensões internas a esse "comando", promovidas por alguns "irmãos" que "desvirtuaram as ideias", começaram a transformar o sonho de Sigma em pesadelo. A maioria dos "irmãos" que ele tinha como "companheiros", e cujas condutas admirava, foi assassinada. Diante do que acreditou ser uma situação incontornável, Sigma, tal como outros prisioneiros, retirou-se para outra prisão em busca de um espaço livre das "desvirtuações" a que assistiu. Desse êxodo decorreu a criação de um novo "comando", que tornou possível enfrentar o PCC pela conquista de um território exclusivo; um refúgio para o que ele considera o "verdadeiro proceder". Doravante, para Sigma e seu novo "comando", o PCC passaria a ser um arqui-inimigo.

Por sua vez, Zeta compreende o surgimento do seu "comando" como um acontecimento que pôs em marcha políticas precisas. Tais políticas dariam fim às "opressões" que os presos sofriam do "Estado" e regulariam as relações 60 entre os próprios presos de modo a evitar que as "opressões” partissem deles próprios. Estas disposições acionaram a formulação e operação de uma infinidade de micropolíticas que passaram a ser operadas pelos prisioneiros.

Zeta lembra-se de que havia duas propostas basilares no nascente PCC. A primeira regulava as relações entre aqueles que se põem contra o "Estado", e que recebeu como título a expressão "paz entre os ladrões”. A outra, que se desmembrava em duas, intrinsecamente ligadas, ditava a postura de embate direto contra as forças estatais, e foi designada pelas expressões "bater de frente com a polícia" e "quebrar cadeia”. Com essa última ideia, o PCG manifestava a proposta de empenho para a obtenção de fugas. Tal "comando", então, efetuava-se na busca daquilo que compreendia por "Paz", "Justiça" e "Liberdade".

Não obstante, Zeta, com a distância que hoje o separa daqueles dias intempestivos, avalia que um aspecto pouco compreendido à época assolava as conquistas obtidas por 
seu "comando": o PCC possuía uma estrutura piramidal de poder e sua dinâmica era apoiada em uma rígida hierarquia. Essa formação favoreceu a prevalência de "irmãos" que não eram "humildes", que queriam "mandar" e produzir "lagartos". Deste modo, instalava-se um problema para o próprio PCC. Tratava-se da proliferação, em seu interior, de relações que ele próprio se propunha a combater: a opressão de um preso por outro. Dizia-se que o poder "subiu à cabeça dos fundadores", pois passaram a praticar as "atrocidades" que se propunham combater. Apoiados por essa constatação, uma massa de presos emigrou para unidades prisionais que ainda não estavam sob o jugo dos "fundadores" e lá decidiram formar um novo "comando". Zeta e seus "parceiros" viram nesse movimento de debandada algo que não era "digno"; um acovardamento travestido de coragem que os prisioneiros formadores do outro "comando" exaltaram com pretensa superioridade. Dali em diante, os prisioneiros que fundaram o outro "comando" passariam a ser considerados "coisa" e tidos como arqui-inimigos dos presos que permaneceram no "Partido".

Essa foi a opção de Zeta e de seus "parceiros”. Eles levaram a sério o dito que ecoava nas cadeias: o poder "subiu à cabeça dos fundadores". O problema não residia no PCC, mas naqueles "irmãos" que se corromperam. Portanto, a tarefa de restabelecer os "princípios do Comando" se impunha urgentemente. Surgiram dissidências que passaram a fazer oposição aos que estavam "corrompidos". Zeta estava numa das fileiras dos dissidentes. Lembra que foi uma época de "guerra" interna, durante a qual foram "arrancadas muitas cabeças". Essa "guerra" culminou na tomada de poder por Marcola que, por sua vez, após "escorraçar" os dois fundadores remanescentes (Geleião e Césinha), imediatamente diluiu-o, adicionando o princípio de "Igualdade" aos "ideais do PCC". Desde esse instante limítrofe - a "revolução" de Marcola - até os dias atuais, as relações sociais entre 
os que permaneceram "em sintonia" com o PCC se mantêm sob outro registro político aos olhos de Zeta, já que perpassadas por esse novo "ideal".

A partir do que foi exposto, podemos dizer que, para Sigma, a história do PCC é cortada por algumas mudanças até o final de 1998 e meados de 1999, quando se deu o surgimento do CRBC; já para Zeta só existiu um corte na história do PCC, já no fechamento do ano de 2002: a instituição da "Igualdade" como princípio. Em outras palavras, se para os relativos ao PCC a "fundação", o "estatuto" e as "guerras" (estes dois últimos indicativos de relações de "mando") aparecem "juntos e misturados", para os relativos ao CRBC isso aparece como etapas distintas de um longo processo. Nesse sentido, a "irmandade" de que Sigma lembra saudoso nunca existiu para Zeta, para quem a história do PCC, desde o início, foi transpassada por relações fortemente hierarquizadas, constituindo um bloco histórico que abrange desde 62 a época de "fundação" até a "revolução" proporcionada por Marcola. Deste ponto de vista, o PCC teria se aperfeiçoado ao longo do tempo e "aprendido com os erros do passado". Já para Sigma, o PCC teria surgido repleto de "intenções" positivas e as foi perdendo, gradativamente, no decorrer de sua história, tornando-se o que os presos do CRBC mais desprezam: um "comando de lagartos".

Voltando agora esses dois pontos de vista um contra o outro, podemos apontar para o modo como cada um deles mobiliza conceituações bastante específicas acerca do que é "liberdade" e do que é "igualdade", utilizando-as para classificar positivamente o "comando" ao qual se está relacionado, e negativamente o "comando inimigo". Deste modo, tais noções se convertem em qualificativos de relações que diferenciam, em termos de presença e ausência, redes sociais que estão em "guerra".

Do ponto de vista de Sigma, desde o instante em que alguns "irmãos" passaram a "exturquir" a "população", ou 
seja, os presos comuns, com a desculpa de que estavam angariando recursos para o PCC, instalou-se uma relação de subjugação que suprimia qualquer possibilidade de "igualdade", bem como de "liberdade", naquela rede social. Dali por diante, ou aceitava-se cooperar em proveito dos "irmãos que desvirtuaram" (obtendo suas aprovações e proteções); ou optava-se por evadir daquele "comando" (emigrando para outras paragens do sistema prisional); ou ainda, e por fim, entrava-se num conflito direto (que, de antemão, sabia-se ser um fiasco). Pela primeira opção, tratava-se de aceitar "viver no pano dos bandidão, fazendo tudo que eles querem”. Em outras palavras, seria o mesmo que se converter num "lagarto do PCC”. Em tal conversão está implicada a abdicação de uma relação "de igual" com outrem, porque o "lagarto" obedece ao "bandidão". Mas também se deixa de lado uma relação "livre" consigo mesmo, porque "liberdade de ser lagarto não é liberdade". Pela segunda opção, abria-se a possibilidade de formar um novo "comando", imune às "desvirtuações" postas em movimento no PCC. Assim seria possível "ter liberdade" para cumprir a própria pena do modo que se quisesse, contanto que cada preso arcasse com as consequências de suas escolhas individuais (ser um "traficante", um "usuário de drogas", ou mesmo um "crente"); afinal, os infortúnios de cada escolha não poderiam recair sobre a coletividade. É nessa "liberdade" de escolher o destino da própria "caminhada na prisão" que reside o sentido daquilo que Sigma entende por "igualdade". Enfim, pela última opção, simplesmente se escolhia partir para um confronto mortal. Para Sigma, a primeira e a terceira opções não poderiam ser atualizadas porque contrariam a "força" de sua existência.

Do ponto de vista de Zeta, o sentido das opções que se abriram no instante em que o "poder subiu pra cabeça dos fundadores" é fundamentalmente distinto. Desde que se tornou aguda essa situação, ou se escolhia fugir dos embates que emergiam por toda parte, tornando-se um covarde 
incapaz de "ir para o arrebento", ou optava-se por ir para a "decisão" contra os "fundadores" corruptos; esta última opção trazia, inexoravelmente, a possibilidade de morrer. Ocorre que a primeira opção, do ponto de vista de Zeta, só poderia ser atualizada por três grupos de presos: 1) aqueles que, estando "pelo errado" e na iminência de serem "cobrados", fizeram dessa situação um pretexto para "passar um pano" nas próprias falhas (dali por diante eles esbravejariam que sempre estiveram "pelo certo" e que foram "injustiçados"); 2) aqueles que, não possuindo a "disposição" necessária para "quebrar cadeia" e para "bater de frente com a polícia”, aproveitaram-se da situação para procurar um lugar onde pudessem "gozar cadeia" (dali por diante eles vociferariam contra a grandeza do "Quinze", exatamente porque enxergaram sua mediocridade); 3) aqueles que, ainda que concordando com os princípios do PCC, fugiram do "arrebento" por serem incapazes de pôr à prova a pró64 pria vida durante a "guerra" que se abria (dali por diante eles bradariam que fizeram "várias pelo Comando" e que mesmo assim sofreram conspiração).

$\mathrm{Na}$ atualização efetuada por esses três grupos considerados reside o sentido da noção de "coisa". Ela, por isso, é algo diametralmente avesso à "força” de existência de Zeta, que, precisamente, é investida pelo sentido de "ser ladrão". Mas então o que Zeta entende por "ser ladrão"? A atualização da potência para ser "humilde" - entendido como "não humilhar ninguém" - e ao mesmo tempo "cabuloso" - entendido como "não deixar que ninguém me humilhe" 61 . É nesse sentido que se pode dizer, acompanhando Zeta, que os

\footnotetext{
${ }^{61} \mathrm{O}$ "ninguém" da formulação "não humilhar ninguém" se refere a um universo limitado de pessoas: os relacionados ao PCC. Não estão compreendidos, por exemplo, os "inimigos". Já o "ninguém" da formulação "não deixar que ninguém me humilhe" é ilimitado, pois engloba todos os possíveis outros. Se por um lado existem pessoas humilháveis (talvez por não serem tão pessoas assim; afinal, são "coisa"), por outro lado o "eu" nunca é humilhável.
} 
presos dos três grupos citados acima eram "caras que não eram cabulosos". Se fossem, teriam ficado para arruinar os "fundadores" extorsionários. Alguns do primeiro grupo também não eram "humildes". No outro extremo da "guerra", seguindo o ponto de vista de Zeta, os "fundadores" corruptos haviam se tornado "caras cabulosos demais" e, por isso, atentavam contra as "forças" dos "ladrões" que permaneceram para o grande embate ${ }^{62}$. Consequentemente, tanto os "fundadores" quanto os "coisas" - por motivos inversos - efetuam relações que desarranjam a "igualdade" entre os "ladrões". Se não bastasse, o êxodo dos "coisa”, já naquela época, passava a ser considerado uma negociação com a Secretaria da Administração Penitenciária, uma vez que havia a abdicação do empenho por fugas por parte dos presos em troca da garantia de espaços prisionais cujos acessos fossem impedidos aos presos relacionados ao PCC. A abdicação da vontade de fugir e a aliança com a administração prisional com o fim de obter uma cadeia melhor para se ficar preso são concebidas como um atentado contra o princípio de "liberdade". Por tudo isso, Zeta não reconhecia como condizente à sua própria "força" a possibilidade de fugir ou de temer a morte. Sendo simultaneamente um "cara humilde" (pois repugnava a "cabulosidade" demasiada) e "cabuloso" (uma vez que não se furtava de "ir para a decisão"), sua "força" o impelia a participar da "guerra" contra os "fundadores", um acontecimento que produzia um corte irreversível na história do PCC: a passagem da "Era-Fundadores" para a "Era-Igualdade".

$* * *$

Alguém poderia protestar, agora que nos aproximamos do final deste artigo, que a diferença manifestada pelo modo

\footnotetext{
${ }^{62}$ As noções "humilde" e "cabuloso" foram problematizadas em Marques (no prelo). Uma discussão mais detida dessas noções, relacionadas ao entendimento nativo sobre "ser ladrão", foi apresentada em Marques (2009).
} 
como cada um de nossos personagens compreende a história de "guerras" entre seus "comandos" é apenas uma diferença de versão. Nessa senda, seria preciso postular uma Realidade única, objetivamente dada - aquilo que realmente ocorreu nas "guerras" entre tais "comandos" -, em torno da qual girariam todos os olhos possíveis: os de Zeta, de Sigma, de Delta e de outros milhares. De um lado, o Real, único e absoluto; de outro, as versões, múltiplas e parciais (quando não, distorcidas). Mas esse fundamento, que reduz um ponto de vista a uma mera versão, se distancia diametralmente de nosso procedimento metodológico. Não porque recusamos a existência da realidade. Não é disso que se trata. Mas porque, de acordo com esse procedimento, a matéria-prima (nossos dados) com a qual contamos são, de partida, tão somente os próprios pontos de vista (ou perspectivas) em relações de força. É por isso que evitamos postular a Realidade. Por isso, também, buscamos nos afastar de preten66 sões de "procurar por trás das perspectivas o modo como as coisas realmente eram", justamente porque entendemos que "as coisas, por trás da perspectiva, não eram de jeito nenhum” (Villela, 2004, p. 24).

Ao contar tão somente com pontos de vista, produzidos em relações de força nas quais estão imbricados, lidamos não mais com uma única Realidade, mas com uma multiplicidade de realidades, sempre relativa às perspectivas. É por isso que podemos dizer ser real um PCC que promove a "igualdade". Este é o ponto de vista de Zeta. Mas, ao mesmo tempo, também é real que o PCC seja um aglomerado de "lagartos". Afinal, é este o ponto de vista de Sigma. Em contrapartida, tanto é real que o CRBC seja um refúgio daqueles que "mantêm seu proceder", quanto o fato de tal "comando" reunir aqueles que "não têm proceder". Todas essas formulações são simetricamente reais, exatamente porque são absolutas no interior de seus pontos de vista. 
O que quisemos neste artigo foi promover um deslocamento intenso entre os pontos de vista de Zeta e de Sigma, mostrando que das relações de força que os atravessam são constituídos memoriais e histórias singulares. Por isso, procuramos nos afastar de uma História Universal (Realidade) que se coloca, parcialmente, e a cada vez de um modo diferente, à compreensão de sujeitos postos a caminhar por sobre suas engrenagens. Ao nos apartarmos desta História que se diz per se, uma fantasmagórica História-em-si, encontramos outro norte. "Toda história é uma história-para" - palavras de Claude Lévi-Strauss (1970, p. 296) que nos aparecem como uma dádiva -, que emerge "das narrativas e da experiência particular das comunidades nativas, assim como do mito, ou [d] as 'histórias dos antigos'" (Amoroso, 2006, p. 194) ${ }^{63}$. Procuramos, então, mostrar como estas histórias-para são "alvo de interpretações e lutas" (Villela, 2004, p. 23). De fato, encontramos essa senda no transcorrer de nossa descrição; nos passos de nossos personagens, em seus embates em torno de acontecimentos que cortaram as histórias dos "comandos". Talvez por isso nos seja permitido dizer que o PCC e o CRBC são, entre outras coisas, "domínios de história, cada um dos quais definidos por uma frequência própria e por uma codificação diferencial do antes e do depois" (Lévi-Strauss, 1970, p. 296). Em outros termos, procuramos mostrar como esses coletivos são, eles próprios, regimes de relações de onde emergem processos específicos de constituição memorial e histórica.

\footnotetext{
${ }^{63}$ Neste texto, uma apresentação à tradução parcial de Of mixed blood: kinship and history in Peruvian Amazonia, de Peter Gow, Amoroso aponta para a apropriação que o antropólogo inglês faz da concepção de história cunhada por Lévi-Strauss. Nas palavras de Gow: "Em O pensamento selvagem, Lévi-Strauss argumenta que não pode haver história final porque todas as histórias devem ser referidas a um sujeito particular para quem esta história tem significado. A etnografia, nesse sentido, é a descoberta desses significados dos sujeitos particulares" (Gow, 2006, p. 206).
} 


\section{Karina Biondi}

é doutoranda em Antropologia Social na UFSCar.

\section{Adalton Marques}

é mestre em Antropologia Social pela USP.

\section{Referências bibliográficas}

ADORNO, S.; SALLA, F. 2007. "Criminalidade organizada nas prisões e os ataques do PCC”. Estudos avançados, vol. 21, n 61, pp. 7-29 (Dossiê "Crime Organizado").

AMORIM, C. 1993. Comando Vermelho: a história secreta do crime organizado. Rio de Janeiro: Record.

AMOROSO, M. 2006. "Etnografia e história na Amazônia, por Peter Gow”. Cadernos de campo: revista dos alunos de pós-graduação em antropologia social da USP, $\mathrm{n}^{\circ}$ 14-15, pp. 193-195.

BIONDI, K. 2007a. "Pesquisa em prisões: reflexões acerca da inserção em campo". Anais da I Reunião Equatorial de Antropologia. América equatorial: cultura na contemporaneidade. Aracaju: ABA (1 CD-ROM). .2007b. "Devir-mulher: a desterritorialização da prisão". Anais da XV Jornadas de Jóvenes Investigadores: investigación, integración y desarrollo. San Lorenzo: AUGM [Asociación de Universidades Grupo Montevideo] (1 CD-ROM).

.2008. "A ética evangélica e o espírito do crime". Anais $d a 26^{a}$ Reunião Brasileira de Antropologia: dilema da (des)igualdade na diversidade. Porto Seguro: ABA (1 CD-ROM).

. 2010. Junto e misturado: uma etnografia do PCC. São Paulo: Terceiro Nome.

BOISSEVAIN, J. 1974. Friends of friends: networks, manipulators and coalitions. Oxford: Blackwell.

CHRISTINO, M. 2001. Por dentro do crime: corrupção, tráfico, PCC. São Paulo: Fiúza.

DELEUZE, G.; GUATTARI, F. 2005. "Introdução: Rizoma”. In: Mil platôs: capitalismo e esquizofrenia. Vol. 1. São Paulo: Ed. 34.

FELTRAN, G. S. 2007. "Trabalhadores e bandidos: categorias de nomeação, significados políticos". Revista temáticas, ano 30, vol. 15 , pp. 11-50.

.2008. Fronteiras de tensão: um estudo sobre política e violência nas periferias de São Paulo. Tese de doutorado em Ciências Sociais. Campinas: IFCH/Unicamp. 
GOW, P. 2006. "Da etnografia à história: 'Introdução' e 'Conclusão' de Of mixed blood: kinship and history in Peruvian Amazônia”. Cadernos de campo: revista dos alunos de pós-graduação em antropologia social da USP, no $14-15$, pp. 197-226.

HARDIMAN, D. 1982. “The Indian 'Faction': a political theory examined”. In: GUHA, R. (org.). Subaltern studies I. Delhi: Oxford University Press.

LÉVI-STRAUSS, C. 1970. O pensamento selvagem. São Paulo: Companhia Editora Nacional/Edusp.

LIMA, T. S. 2005. Um peixe olhou para mim: o povo Yudjá e a perspectiva. São Paulo: Ed. Unesp/ISA; Rio de Janeiro: NuTI.

MARQUES, A. 2006. "Proceder": "o certo pelo certo" no mundo prisional. Monografia de Graduação em Sociologia e Política. São Paulo: FESP-SP. .2008. “'Faxina' e 'pilotagem': dispositivos (de guerra) políticos no seio da administração prisional”. Lugar comum: estudos de mídia, cultura e democracia, Rio de Janeiro: Universidade Nômade, vol. 25-26, pp. 283-290.

.2009. Crime, proceder, convívio-seguro: um experimento antropológico a partir de relações entre ladrões. Dissertação de Mestrado em Antropologia Social. São Paulo: FFLCH-USP.

. no prelo. “'Liderança', 'proceder' e 'igualdade’: uma etnografia das relações políticas no Primeiro Comando da Capital”. Etnográfica, Lisboa.

MINGARDI, G. 1998. O Estado e o crime organizado. São Paulo: IBCCRIM.

NICHOLAS, R. W. 1977. "Factions: a comparative analysis". In: SCHMIDT, S. W.; GUASTI, L.; LANDÉ, C. H.; SCOTT, J. C. (orgs.). Friends, followers, and factions: a reader in political clientelism. Berkekey/Los Angeles/London: University of California Press.

PALMEIRA, M. 1996. "Política, facções e voto". In: GOLDMAN, M.; PALMEIRA, M. (orgs.). Antropologia, voto e representação política. Rio de Janeiro: Contra Capa.

SARTORI, G. 1987. Partidos e sistemas partidários. Brasília: Ed. UnB.

SCHMIDT, S. W.; GUASTI, L.; LANDÉ, C. H.; SCOTT J. C. (orgs.). 1977. Friends, followers, and factions: a reader in political clientelism. Berkekey/Los Angeles/London: University of California Press.

SWARTZ, M. J. (org.). 1968. Local-level politics. Chicago: Aldine Publishing Company.

VILLELA, J. M. 2004. O povo em armas: violência e política no sertão de Pernambuco. Rio de Janeiro: Relume Dumará.

VIVEIROS DE CASTRO, E. 2002. A inconstância da alma selvagem: e outros ensaios de antropologia. São Paulo: Cosac \& Naify. 


\section{Outros materiais}

MANO BROWN et al. 2002. "Negro drama". In: Racionais MC's: nada como um dia após o outro dia. São Paulo: Unimar Music. CD 1, faixa 5. (2 CD's). 


\section{MEMÓRIA E HISTORICIDADE EM DOIS “COMANDOS” PRISIONAIS}

KARINA BIONDI

ADALTON MARQUES

$\mathrm{O}$ artigo apresenta um embate fictício (o que não quer dizer que seja irreal) entre um prisioneiro relacionado ao Primeiro Comando da Capital (PCG) e outro, ligado 
ao Comando Revolucionário Brasileiro da Criminalidade (CRBC). O intuito é mapear diferentes historicidades acerca dos "comandos" prisionais em São Paulo. O diálogo tenso e violento entre esses prisioneiros opera um choque de seus pontos de vista, significativamente opostos. Nesse exercício, revelam-se realidades distintas - porém não contraditórias -, constituídas a partir de diferentes memoriais sobre as "guerras" que envolveram os citados "comandos".

Palavras-chave: Prisioneiros; CRBC; PCC; Historicidade; Realidade; Pontos de vista.

\section{MEMORY AND HISTORICITY IN TWO PRISIONAL COMMANDS}

This article presents a fictional encounter (which does not mean it's not real) from a prisoner related to the Primeiro Comando da Capital (PCC - First Capital Command) and other, linked to the Comando Revolucionário Brasileiro da Criminalidade (CRBC 238 Brazilian Revolutionary Command Crime). The motif is to map different historicities about prison's “commands" in São Paulo. The tense and violent dialogue between them operates a shock of their viewpoints, significantly opposite. This exercise reveal different realities - but not contradictory -, formed from different memorials on the "wars" involving the aforementioned "commands".

Keywords: Prisoners; CRBC; PCC; Historicity; Reality; Viewpoints. 